\title{
La música popular en las elecciones generales de 2019 en España
}

\section{Popular Music in the 2019 Electoral Campaign in Spain}

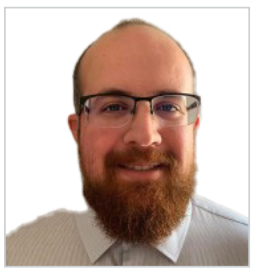

Antonio Francisco Alaminos Fernández. Investigador del Instituto de Desarrollo Social de la Universidad de Alicante. Doctor en el programa de Empresa, Economía y Sociedad (Universidad de Alicante), Grado en Publicidad y RR.PP. (Universidad de Alicante), Grado en Ciencias Sociales y del Comportamiento (MU), Bachelor en Circumpolar Studies (University of Nordland), Máster Internacional en Paz, Conflicto y Desarrollo (Universitat Jaume I), Master of Arts with a Major in Communication for Development (Malmö Universitet, Sweden). Especialista en la investigación de la música y sus efectos: Emociones, valores e identidades. Áreas: Música y movimientos sociales, diplomacia de las celebridades, comunicación, técnicas de investigación, estereotipos, publicidad y música ambiental. Autor de diversos artículos sobre música, política y comunicación. Estancias de investigación en GESIS (Alemania) y Glasgow Caledonian University (Escocia).

Universidad de Alicante, España

Antonio.alaminos@ua.es

ORCID: 0000-0002-4606-4646

Recibido: 30/11/2020 - Aceptado: 10/04/2021 - En edición: 08/05/2021 - Publicado: 14/06/2021 Resumen:

Esta investigación indaga en el diseño de las playlists electorales de tres partidos en las elecciones generales de 2019 en España. El binomio partido-candidato es esencial para entender la función de la música popular en las campañas electorales. El himno es una imagen de marca sonora del partido que apela a votantes fieles y enmarca en campaña al candidato. Las playlists con música popular permiten un discurso dividido emocional y temáticamente que facilita la personificación del partido. El empleo funcional de las canciones en las playlists se desarrolla desvinculando la canción utilizada de la ideología del intérprete. Tomando como referencia los estilos musicales, los temas de las letras y las fechas de las canciones, se observa que electoralmente el PSOE se dirige a los jóvenes con mensajes sociales de actualidad, y el PP, generacionalmente más amplio, usa la nostalgia y la identidad en la lógica de recuperar antiguos votantes. Ciudadanos abunda en la época de la denominada Movida, en la captación de electorados maduros, así como algunos jóvenes. En cualquier caso, lo que es destacable es la escasez de propuestas políticas, el predomino del mensaje emocional, que al ser atribuible a las organizaciones políticas y no a los candidatos, fortalece la vinculación con el partido.

\section{Palabras clave:}

Comunicación política; música popular; playlist electoral; emociones.
Received: 30/11/2020 - Accepted: 10/04/2021 - Early access: 08/05/2021 - Published: 14/06/2021 Abstract:

This research study the design of the electoral playlists of three parties for the general elections of 2019 in Spain. The pair formed by party and candidate is essential to understand the role of popular music in electoral campaigns. The anthem is the party's sound brand that appeals to loyal voters and frames the candidate in the campaign. Playlists with popular music allow for an emotional and thematic bifid speech that facilitates the personification of the political party. The functional use of the songs in the playlists is based by unlinking the song used from the ideology of the interpreter. Based on the musical styles, the themes of the lyrics and the dates of the songs, it is observed that electorally the PSOE addresses young people with current social messages; the PP, uses nostalgia and identity in the logic of recovering former voters, with a broader generational orientation. Ciudadanos abound at the time of the so-called Movida attracting mature and young electorates. In any case, the scarcity of political proposals is notable, the predominance of the emotional message, which, being attributable to the political parties and not with candidates, strengthens ties with the party.

\section{Keywords:}

Political communication; popular music; electoral playlist; emotions.

Cómo citar este artículo:

Alaminos Fernández, A. F. (2021). La música popular en las elecciones generales de 2019 en España. Doxa Comunicación, 32, pp. 225-249. https://doi.org/10.31921/doxacom.n32a11 


\section{Introducción}

El empleo de la música en las campañas electorales ha sido documentado para los Estados Unidos de América desde finales del siglo XVIII (Kasper y Schoening, 2012). Es evidente que tanto su uso como las formas de las composiciones han cambiado con el tiempo. Desde las composiciones con un estilo propio de una marcha de coronación en las elecciones de 1789 hasta las canciones del grupo Village People utilizadas por Trump en sus campañas de 2016 y 2020, han pasado casi dos siglos y medio. A pesar de la tradición musical en campañas electorales tanto en Estados Unidos como en otras democracias, el estudio de este fenómeno comunicativo es relativamente reciente. Especialmente para el caso español, donde la investigación sobre el empleo de música en campañas electorales es aún incipiente.

De hecho, a pesar de lo significativas que fueron determinadas melodías como parte de la transición a la democracia, pensemos en "Libertad sin ira", la música popular adquirió para los partidos mayoritarios el papel secundario de ambientación de evento. En los partidos mayoritarios, las canciones comerciales con mensaje político pasan a un segundo lugar desplazadas por el peso fundamental del himno del partido. En el caso del PSOE, en 1982 compone Julio Mengod su himno actual, siendo el del Partido Popular de Manuel Pacho, compuesto a principios de los 90 para relanzar y actualizar su imagen. Estos himnos han sido versionados varias veces, generalmente coincidiendo con las campañas electorales, trasmitiendo la impresión de novedad y cambio. El himno del partido se convierte en imagen sonora de marca y carta de presentación pública. Este enfoque es apropiado cuando los electores son relativamente estables y fieles a un partido y la principal tarea es motivar la movilización. En términos musicales, con los himnos el partido enmarca al candidato.

Sin embargo, en los últimos años en España la música popular amplía de forma sustantiva sus funciones en la campaña. Además de ayudar al reconocimiento de marca y la activación emocional, la música se convierte en parte del discurso que intenta conectar electores y partidos políticos. Es un giro que sintoniza las campañas electorales españolas con la de otras democracias, en parte como consecuencia de la transformación de los electorados. Tras las movilizaciones sociales de 2011 los electorados españoles han experimentado cambios muy significativos, debilitándose los anclajes partidistas e incrementándose la volatilidad y la desmovilización. La existencia actual de cinco partidos, que han sido o son significativos electoralmente en las dos últimas elecciones de 2019, son una evidencia de la fragmentación y por lo tanto de una nueva configuración. Este hecho, la pérdida de fidelidad de una parte significativa de los votantes, nos aproxima a otras culturas políticas en las que la indecisión del electorado es el elemento clave.

En democracias con regímenes presidenciales, las canciones han actuado como un procedimiento para atribuir rasgos de carácter a los líderes políticos. Un caso especialmente paradigmático el presidente Obama. La música popular fue un elemento clave de su imagen, ya sea como intérprete o utilizando las plataformas para publicar sus listas de reproducción. Unas listas calibradas a la perfección por épocas, estilos, género de los intérpretes e idiomas para dar una imagen muy concreta de líder cool (Alaminos-Fernández, 2018, 2020). Biden, siendo vicepresidente con Obama publicó sus propias playlists, usando para las elecciones presidenciales de 2020 la misma estrategia. Una lista que ofrecía múltiples puentes y conexiones con los electorados significativos (afroamericanos o hispanos). Las canciones populares amplían su función más allá del "musical branding" del candidato, mediante el que atribuyen cualidades y rasgos de carácter, abriendo múltiples conectores emocionales con la sociedad. 
En esa función ampliada es como ha llegado la música popular a las últimas campañas electorales en España. Se establece un binomio entre el himno del partido (apelación a los fieles) y las listas de canciones comerciales. Estas expresan un mensaje emocional más diverso combinable con la focalización temática que se desee comunicar. En España, para las dos elecciones generales de 2019 algunos partidos políticos han publicado sus playlist de campaña.

Esta investigación considera la música de campaña de tres partidos de ámbito nacional: Ciudadanos, Partido Popular y Partido Socialista Obrero Español. Los tres partidos han creado listas musicales en la plataforma Spotify con ocasión de las dos elecciones generales celebradas en el año 2019 e ideológicamente están ubicados entre el centro izquierda, el centro derecha y la derecha. En el caso de Unidas Podemos o Vox, aun cuando es fácil apreciar el discurso ideológico de un partido que emplea en campaña el himno militar Soy el novio de la muerte o canciones protesta de la época de la transición, al no publicar listas que puedan considerarse un mensaje formalizado, no han sido consideradas por falta de datos comparables. En ese sentido, estudiamos aquí la comunicación electoral empleando música comercial por parte de partidos que se mueven en la zona más templada del espectro ideológico con canciones que definen un discurso bífido, expresando tanto lo emocional como los temas que le identifican.

\subsection{La música y las elecciones}

La música está presente en las campañas electorales, con un papel u otro dependiendo del sistema político y la situación social. En el panorama internacional, las elecciones presidenciales de Estados Unidos de América muestran una larga tradición de uso de la música en las campañas (Schoening y Kasper, 2012). Hasta el punto de que uno de los conceptos analíticos de la dinámica electoral, bandwagon, hace referencia al coche que llevaba a los músicos acompañando la campaña. Una primera observación se refiere al papel que juega la música dependiendo de la relevancia que en el sistema político tengan los líderes o los partidos. En sistemas presidencialistas la música ofrece un papel muy importante en atribuir rasgos y características a los candidatos. Algo que se ha denominado "musical branding" en la medida que se considera el candidato presidencial como una marca, una imagen que debe arroparse y definirse (Busby, 2009; Love, 2012). Los casos de Estados Unidos o Francia son muy característicos de la centralidad que la música adopta en relación con elecciones muy personalizadas. Esto también ha sucedido en el caso español donde, ocasionalmente, aparece lo que se denomina "canción presidencial".

Otra situación diferenciada se encuentra en aquellas elecciones en las que los partidos y los líderes ocupan espacio más equilibrado. Si bien la figura del líder es fundamental en tanto que atractor electoral, la tradición les concede un peso significativo a los partidos políticos en la dinámica electoral. Esta mayor presencia de la imagen de partido en el caso de España se evidencia en la existencia de himnos que ambientan las campañas o actos de partido. Los himnos del partido son los que actúan como marca y referencia musical para activar la vinculación emocional.

Junto a los himnos de partido ocupan un lugar significativo las canciones populares de naturaleza comercial. Las canciones constituyen una herramienta para establecer puentes emocionales con los electores (Love, 2016), así como una

1 Canción "RAJOY CONTIGO ESTOY” en las elecciones generales de 2008 https://www.youtube.com/watch?v=JOIV_Ba9Iig\&ab_channel=aldelcorral (Consultado el 21/02/2021) 
llave para activar la memoria y recordar sentimientos pasados (Alaminos-Fernández, 2021). En ese sentido, el empleo de canciones va más allá de la construcción de marca de los candidatos y apela a la activación y movilización de identificaciones con el partido. En el caso español con una situación electoral donde los votantes se alejan de la política, la volatilidad es elevada y los argumentos racionales pierden peso respecto a los emocionales, el discurso musical adquiere una mayor utilidad (Fouce y del Val, 2017; Quecedo, 2017; Espí Hernández, 2017; Panke, 2019; García, 2019; Jaráiz et al. 2020; Alaminos, 2021).

La utilización de canciones preexistentes implica un conjunto de restricciones al diseño de las playlist de los partidos (Love, 2012), en la medida que la industria musical es un mercado con reglas de composición condicionadas por lo comercial (Adorno, 1941; Taylor, 2016). Esto lleva a que las canciones se utilicen en su versión original o adaptadas a los objetivos políticos trasformando su significado. Dichos cambios pueden modificar las letras de las canciones o reproducirlas en un contexto que les atribuye un significado que no corresponde con el original. Es lo que Rolston (2001) denomina deriva lírica o desvío de palabras y que consiste en modificar el sentido original de una canción para darle uno nuevo reinterpretándola en otro contexto. Esta deriva alcanza un grado máximo cuando la letra se ve alterada para su uso político. Así, en España el partido político Vox empleó la canción de Juanes A dios le pido versionada como A Vox le pido. Al igual que sucedió en Estados Unidos con Reagan y su empleo del tema de Springsteen Born in the USA, Juanes reclamó que se respetara el significado original de la canción. Aquí, en este caso, las canciones son utilizadas independientemente del compromiso político con un partido que pueda expresar el artista, traduciendo emocionalmente el mensaje de acuerdo con los objetivos de campaña.

\subsection{Música en campaña y música de campaña}

Una distinción importante es la diferencia entre música de campaña y música en campaña (Alaminos-Fernández, 2016). Si bien la canción y el intérprete tienden a formar una unidad de significado, la diferencia entre la música de campaña y la música en campaña procede de la voluntad de compromiso político con un partido. En la música en campaña los músicos actúan como celebridades que ponen su fama al servicio de un partido o causa (Orman y West, 2003; Wheeler, 2013). Burke (1969) basándose en la teoría de la identificación proponía que si un segmento de la población (según edad, género, etc.) se identifica con un artista, mostrará una probabilidad elevada de reproducir las preferencias políticas del artista. No obstante, los datos que avalan dicha afirmación son excesivamente antiguos y faltan evidencias sobre su validez en las sociedades actuales. Según Wheeler (2013), una parte importante de las investigaciones actuales indaga precisamente en las formas como las celebridades están participando en política y viceversa, cómo los políticos se comportan y actúan como si fuesen celebridades. Esa zona de contacto borrosa entre músicos famosos y políticos establece el campo de la colaboración electoral. Hasta el punto de que según Orman y West, (2003) la distinción desaparece cuando los músicos famosos apoyan y recaudan fondos para candidatos políticos, intentando trasmitir los rasgos positivos de su fama como celebridades a los políticos que apoyan, expresando su posicionamiento ideológico.

En España un ejemplo de esto lo encontramos en la Plataforma de apoyo a la candidatura de José Luis Rodríguez Zapatero en las elecciones generales de 2008. Músicos como Ana Belén, Víctor Manuel o Serrat, junto a otros personajes famosos procedentes de otros ámbitos, solicitaron el voto y el apoyo electoral a la candidatura del Partido Socialista Obrero Espa- 
ñol. Esta actuación es habitual en las campañas electorales norteamericanas, donde los personajes famosos establecen plataformas de apoyo, por lo general a candidatos progresistas.

En ese sentido, si consideramos la situación en España, se observa cómo sucede algo semejante a los Estados Unidos de América; tanto allí como en España es más fácil encontrar músicos famosos que apoyen al Partido Demócrata, o a partidos progresistas, que a partidos de derechas o conservadores. Precisamente una queja explícita de los comités de campaña de Donald Trump, en sus dos elecciones presidenciales, es la dificultad de encontrar músicos famosos que apoyen la candidatura, mientras que al Partido Demócrata se ofrecen para actuaciones gratuitas.

Cabe considerar que por lo general, los músicos prefieren no comprometerse políticamente, ya sea porque les crea dificultades para ser contratados por la administración pública para ofrecer conciertos porque generan el rechazo de parte de la audiencia. Precisamente, tanto los actos de apoyo a partidos como las actuaciones de censura han sido utilizados en esta investigación para operativizar la medición de las posibles afinidades ideológicas de los músicos. Un ejemplo de esto fue la censura por el nuevo gobierno del Partido Popular de 21 artistas, retirándolos del cartel de las fiestas de San Mateo de 2019 en Oviedo.

En la música de campaña se emplean los recursos musicales por sus propios significados semánticos o emocionales, sin apelar a la fama de sus intérpretes. Las canciones son, por sí mismas, un elemento habitual en la vida cotidiana y definen una herramienta con capacidad de establecer empatía emocional. Las canciones producen por sí mismas efectos cognitivos y emocionales que proceden de las letras, las melodías, los estilos musicales, la época que referencia o incluso el idioma utilizado. En general, los idiomas connotan emociones y sensaciones muy definidas en términos de estereotipos culturales (Bechini, 1985; Alaminos-Fernández, 2014). Posiblemente, el idioma es un elemento de connotación cultural que aporta múltiples dimensiones a una canción, entre ellas "idiosincrasia” y una "denominación de origen" en la medida que posee sus propias cualidades en los imaginarios sociales. El género musical de la canción, así como la imagen del idioma configuran, en sí mismos, un mensaje, complementario al contenido de las letras. Las canciones tienen la capacidad de actuar como gatillos emocionales al ser portadoras de vivencias y activar evocaciones (Alaminos-Fernández, 2021).

Los posibles efectos de las canciones, cuando la tienen, son el resultado de una combinación entre música y letra. Un elemento sustancial que es con frecuencia olvidado en los estudios interesados por los efectos emocionales de la música y que tienden a concentrarse casi exclusivamente en los rasgos musicales de las canciones (Juslin, 2005; Alaminos-Fernández, 2019). Las letras, cuando son comprendidas por la audiencia, son una fuente evidente de socialización en valores o comportamientos según la teoría cognitiva del aprendizaje (Giles y Maltby, 2004; Harakeh, Scholte, Vermulst, de Vries, y Engels, 2004; Maxwell, 2002; Petraitis et al., 1995). Sin embargo, aunque la mayoría de las canciones tienen letra, no existen demasiados estudios sobre ellas (Juslin, 2005; Mori y Iwanaga, 2014; Stratton y Zalanowski, 1994). En todo caso, las conclusiones a las que llegan están lejos de ser consistentes. Por ejemplo, Straton y Zalanowski (1994) al comparar los efectos emocionales de la exposición a música sin letras y canciones con letras, concluyen que las canciones que tienen letra producen un mayor efecto emocional. Los intentos por replicar dichos resultados (Sousou, 1997) no alcanzaron un resultado positivo, atribuyendo las diferencias al empleo de diferentes canciones. Sin embargo, de ser ese el factor determinante, indirectamente invalidaría las conclusiones del anterior estudio al ser dependientes de las canciones elegidas. 
Evidentemente el estudio sobre los efectos de las canciones en las emociones se hace más complejo cuando se introducen elementos textuales, que representan las letras, junto con la dimensión instrumental (Mori y Iwanaga, 2013). Además, los factores personales y de contexto introducen una variabilidad importante en los efectos de la interacción entre las letras y las melodías (Schlegel, 1999). En ese sentido, varios estudios (Baltes, Avram, Miclea, y Miu, 2011; Brattico et al., 2011; Mory y Iwanaga, 2013) indican que existe un efecto de las letras que actúa sobre las emociones sentidas por las audiencias. A esto debe sumarse que las formas en que músicas y letras se combinan son con frecuencia un reflejo de las normas culturales, como estilos de vida (Rothbaum y Tsang, 1998). Así para el caso de géneros como el pop o el rock su impacto emocional está claramente vinculado a la relación existente entre la música y las letras (North et al., 2004; Rentfrow y Gosling, 2003).

En lo que se refiere al papel que juegan las letras de las canciones en la vida cotidiana, son varios los estudios que han investigado con respecto a cómo estas pueden ayudar a los individuos a conocer mejor sus sentimientos, adoptar una posición con respecto a determinados temas o ayudar a contribuir a tomar una decisión en presencia de dificultades (Hargreaves, Miell, y MacDonald, 2002; Gibson, Aust, y Zillman, 2000). Este elemento es muy significativo en los climas políticos caracterizados por una elevada volatilidad e incertidumbre entre los votantes.

Asimismo, según Dewall, Pond y Capmpbell (2011), se ha incrementado el estudio sobre los contenidos de las letras de las canciones en relación con comportamientos antisociales o críticos con el sistema económico o político, disminuyendo los estudios que indagaban sobre la representación de las relaciones sociales. Sin embargo, es evidente que las emociones románticas continúan siendo el tema de referencia en muchos estilos comerciales.

Las letras de las canciones representan una fuente de información muy significativa tanto sobre la realidad social como sobre los deseables que existen o las líneas de ruptura y conflicto existentes. Para algunos autores, existe una propensión al consenso social de tal forma que las canciones más frecuentes contienen letras sobre posiciones y temas que reciben una mayor aceptación para el conjunto de la sociedad (Health, Bell y Sternberg, 2001). En el caso de la música que emplean los partidos políticos para conectar con sus electorados, los temas y su significado social y cultural adquieren una importancia elevada.

\section{Objetivos y metodología}

La música utilizada en el ámbito de la política, y más en particular en lo electoral, indica dos aspectos fundamentales. Por una parte nos habla de la sociedad y por otra del propio partido. En lo que se refiere a la sociedad nos ofrece una foto de los electorados (segmentos de población) a los que apelan los partidos, los valores y emociones que considera son relevantes para ellos. En ese sentido, el cambio social encuentra su expresión en la sucesión de estilos musicales que se asocian con lo vivido en cada momento, tanto individualmente como en términos generacionales. En el caso español, los periodos más significativos se refieren a la etapa franquista y posfranquista, la transición y la denominada movida (Labrador y Monasterio, 2006; Fouce y Pecourt, 2008; Fouce, 2009; Alonso, 2010; Mora y Viñuela, 2013; García, 2017).

En lo que se refiere al partido, opera en términos de expresar una imagen de partido, al igual que sucede con las listas musicales de los candidatos presidenciales (caso de los Estados Unidos de América) así como de establecer conexiones 
emocionales. Compartir música humaniza la política y aproxima emocionalmente a los candidatos a los electores bajo el argumento no enunciado explícitamente de "nos gusta la misma música", sentimos lo mismo, nos parecemos. Al mismo tiempo, decanta de forma simplificada qué perfiles y temas quiere que caractericen su imagen. En el proceso de determinar los aspectos anteriores a partir de las listas de canciones que los propios partidos han seleccionado se han formulado una serie de preguntas.

\subsection{Objetivos}

El primero de ellos es hasta qué punto son diferentes las listas musicales de los tres partidos. Compartir un número elevado de canciones e intérpretes indicaría que las listas definen preferencias musicales casi aleatorias, sin mayor intención que una diversión genérica. Listas diferenciadas aportaría evidencias sobre la existencia de una distinción entre las audiencias, donde incluso en el caso de que las canciones sean elegidas para la diversión, mostraría que las audiencias se divierten con canciones o estilos musicales distintos. En todo caso, la respuesta afirmaría la diferencia pero no la intención. Para el análisis de las listas de los tres partidos se han considerado todas las canciones, independientemente del idioma.

Así, en lo que se refiere a la posible intencionalidad, cabe plantear la pregunta alternativa, es decir si es posible detectar contigüidades ideológicas entre partidos según sus listas musicales de campaña. La proximidad o competición por un espacio político (especialmente en el centro derecha) podría expresarse en forma musical. En otras palabras, si las canciones son vehículos para conectar con los electorados y una carta de presentación del partido, deberían darse mayores coincidencias en los mensajes que envían a electorados compartidos. Es decir, en las canciones o intérpretes. En el caso que se compartan más canciones de las listas entre partidos ideológicamente contiguos, abundaría en la evidencia de intencionalidad del diseño.

El segundo objetivo es determinar la presencia del factor "música de campaña" junto a la "música en campaña". Para ello se evaluará si interviene la ideología de la celebridad en la selección de las canciones. Por ejemplo, si los intérpretes que apoyaron la plataforma a Zapatero (Partido Socialista Obrero Español) están en las listas de canciones del Partido Popular o Ciudadanos. En general, son pocos los intérpretes musicales que explícitamente muestran una militancia ideológica. Cuando esta se produce, una selección musical que excluya intérpretes según afinidad ideológica estaría presente la música en campaña, donde el intérprete contribuye significativamente junto a la canción.

La tercera cuestión es qué canciones caracterizan a cada uno de los partidos y qué expresan en términos de electorados y de imagen del partido. Según Brownell (2014 y 2015) "A lo largo de los años, a través del nacimiento de nuevas formas de comunicación y entretenimiento que han hecho de las campañas electorales verdaderos espectáculos, las listas de reproducción se han convertido en un elemento crucial para comprender los valores que cada candidato quiere representar y comunicar". En esta investigación vamos a considerar como indicadores clave el estilo musical, la época y los temas de las canciones. 


\subsection{Metodología y datos}

Las preguntas que plantea la investigación requieren considerar que las listas de cada partido están formadas por dos subpoblaciones en función del idioma: canciones con letras en español y canciones con letras en idiomas extranjeros. Así, los análisis de listas para determinar el posible perfil musical diferenciado de cada partido utilizan la población completa, mientras que otras preguntas requieren considerar exclusivamente las canciones en español, dado que envían junto al emocional un contenido comprensible para la población general.

Para responder a las preguntas anteriores se utilizan las tres listas de canciones reproducidas en los mítines y actos electorales, disponible en la plataforma Spotify. La muestra viene formada por las canciones que componen las listas La España ${\text { que } \text { quieres }^{2} \text { del PSOE, \#valorseguro }}^{3}$ del Partido Popular y Ciudadanos ${ }^{4}$ de Ciudadanos. Una lista musical de campaña compuesta por 263 intérpretes o grupos musicales y con 287 canciones diferentes.

Tabla 1. Número de canciones en las playlist en las elecciones generales de abril-noviembre de 2020

\begin{tabular}{|l|c|c|}
\hline Partidos Políticos & Número de canciones & Porcentaje \\
\hline PSOE & 100 & 33,6 \\
\hline PP & 100 & 33,6 \\
\hline Ciudadanos & 98 & 32,9 \\
\hline Total & 298 & 100 \\
\hline
\end{tabular}

Fuente: Spotify

Considerando la presencia de idiomas extranjeros en las tres listas, el $48 \%$ de las canciones tienen letras en inglés y un $0,3 \%$ en francés. Es notable que en una campaña electoral en España casi la mitad de las canciones estén en un idioma diferente al de los electores. Respecto a los idiomas extranjeros, los tres partidos considerados usan predominantemente el inglés, con un 30\% de las canciones del PSOE en este idioma, el 52\% de la lista del PP y el 57,1\% en las de Ciudadanos. Solamente el Partido Popular incorpora una canción en francés, Non, je ne regrette rien, de Édith Piaf.

El castellano es el idioma preponderante en las playlist electorales del PSOE, y en menor medida del Partido Popular y Ciudadanos. Aparecen de forma testimonial canciones con letras en catalán, euskera, gallego y asturiano. El PSOE introduce en sus listas canciones interpretadas en catalán, euskera y asturiano, mientras que el PP lo hace con una canción en lengua gallega. Ciudadanos solamente utiliza canciones en castellano.

\footnotetext{
Recuperado de: spotify:playlist:3BgANY10AAu35GNoMD3Zdq (Consultado el 21/02/2021).

Recuperado de: spotify:playlist:08jpakSuzMTW2Sqstxj0Lm (Consultado el 21/02/2021).

Recuperado de: spotify:playlist:60NewTmpC9Wp1Qzk1iUTTx (Consultado el 21/02/2021).
} 
Tabla 2. Porcentaje de canciones en las playlist según idioma y partido en las elecciones generales de abril-noviembre de 2020

\begin{tabular}{|l|c|c|c|c|}
\hline & PSOE & PP & Ciudadanos & Total \\
\hline Catellano & $63,0 \%$ & $45,0 \%$ & $41,8 \%$ & $50,0 \%$ \\
\hline Inglés & $33,0 \%$ & $53,0 \%$ & $58,2 \%$ & $48,0 \%$ \\
\hline Euskera & $2,0 \%$ & & & $0,7 \%$ \\
\hline Gallego & & $1,0 \%$ & & $0,3 \%$ \\
\hline Catalán & $1,0 \%$ & & & $0,3 \%$ \\
\hline Asturiano & $1,0 \%$ & & & $0,3 \%$ \\
\hline Francés & & $1,0 \%$ & & $0,3 \%$ \\
\hline Total & $100 \%$ & $100 \%$ & $100 \%$ & $100 \%$ \\
\hline
\end{tabular}

Fuente: elaboración propia

Para el análisis del primer objetivo, perfilar la imagen del partido, se han considerado todas las canciones. Los otros dos objetivos emplean para el análisis las canciones en castellano, al ser los contenidos de las letras de comprensión general. Por ello, las codificaciones de los estilos o la tematización de las letras se han realizado para la subpoblación de canciones en idioma español.

La codificación ideológica de los intérpretes, la categorización de los estilos musicales y la tematización de los contenidos han seguido los siguientes criterios. Los intérpretes han sido, en la medida que la información disponible lo hace posible, clasificados en los espacios de izquierda y derecha ideológica. Como ya se ha comentado, muchos intérpretes evitan expresar un compromiso con partidos políticos o incluso con causas sociales, para evitar posibles daños a sus carreras profesionales. Se ha efectuado una intensa búsqueda de declaraciones y otros indicadores que expresaran rasgos ideológicos. Por ejemplo, cuando los músicos han actuado en mítines o plataformas de apoyo político o, por el contrario, en el caso de que los músicos han sido censurados por otros partidos por atribuirles rasgos ideológicos.

Tabla 3. Posicionamiento ideológico de los intérpretes en las playlist electorales

\begin{tabular}{|l|l|c|c|}
\hline \multicolumn{2}{|c|}{} & Frecuencia & Porcentaje \\
\hline \multirow{4}{*}{ Intérpretes } & Progresista & 33 & 21,9 \\
\cline { 2 - 4 } & Conservador & 15 & 9,9 \\
\cline { 2 - 4 } & Sin atribuir & 103 & 68,2 \\
\cline { 2 - 4 } & Total & 151 & 100,0 \\
\hline
\end{tabular}

Fuente: elaboración propia 
En lo que se refiere a las canciones, tanto los temas tratados como la asignación de un estilo se han considerado indicadoras de la imagen que aspira a ofrecer el partido político. Considerando los diversos estilos de las canciones en las playlist electorales, se han clasificado en tres grandes tipos según su significado cultural en el panorama musical español. Son los estilos que se pueden denominar tradicionales, los estilos asociados a la modernidad y los estilos más actuales identificativos de la cultura más juvenil.

La categoría de estilos tradicionales incluye a las sevillanas, la copla, el pasodoble, flamenco o rumba. Son estilos musicales idiosincráticos característicos de la cultura española tradicional. Los estilos "modernos" identifican los géneros que si bien actualmente son convencionales, representaron un cambio importante en la cultura de la década de los 60 en España. Estos son fundamentalmente el pop y el rock. Son estilos familiares a una población de amplio espectro sociodemográfico. Por último los nuevos estilos formados por las músicas más recientes, con un marcado carácter juvenil, como son el dance, la música electrónica, el electropop, hip-hop/rap, house, música alternativa/indie o el reguetón.

Tabla 4. Estilos musicales de las canciones en las playlist electorales

\begin{tabular}{|l|c|c|}
\hline & Frecuencia & Porcentaje \\
\hline Nuevos estilos subculturales & 33 & 22,1 \\
\hline Estilos modernos mainstream & 104 & 69,8 \\
\hline Estilos tradicionales & 12 & 8,1 \\
\hline Total & 149 & 100,0 \\
\hline
\end{tabular}

Fuente: elaboración propia

Una cuestión significativa es la no presencia de determinados estilos musicales. Así, no están presentes el punk, el country o el jazz. Los estilos más utilizados son sobre todo de amplia audiencia y de ellos, la mayoría presentes en los 40 principales a lo largo del tiempo.

El análisis de contenido de las letras ha permitido la tematización atendiendo al objeto de las canciones presentes en las listas. Se observan cuatro categorías principales. La primera categoría se refiere a los "estados de ánimo personales" y la segunda "emociones románticas de pareja". En las emociones románticas de pareja se codifican todas las canciones donde la relación es o se deduce heterosexual. Cuando la relación es homosexual se incluye en la tercera categoría denominada "sociopolíticas sectoriales", donde se considera temas como el empoderamiento femenino, la violencia de género, ecología, la desigualdad, libertad sexual, etc. La cuarta categoría, "sociopolíticas identitarias" incluye los temas que ensalzan la identidad española, tanto nacional como local. Por ejemplo "Y viva España" o "Sevilla tiene un color especial". Estas categorías son, en la práctica, una expresión aproximada de lo que ha sido y es el panorama musical en España. 
Tabla 5. Temas de las canciones en las playlist electorales

\begin{tabular}{|l|c|}
\hline & Total \\
\hline Estados de ánimo personales & $33,6 \%$ \\
\hline Emociones románticas pareja & $46,3 \%$ \\
\hline Sociopolíticas sectorial & $14,8 \%$ \\
\hline Sociopolíticas identitarias & $5,4 \%$ \\
\hline Total & $100 \%$ \\
\hline
\end{tabular}

Fuente: elaboración propia

La metodología utilizada tanto para la construcción de las categorías analíticas como para su estudio es el análisis de contenido de las listas musicales de los tres partidos. Tras la codificación se han realizado análisis estadísticos mediante análisis de correspondencias con la finalidad de identificar la estructura relacional presente en los datos.

\section{Análisis}

El análisis de los datos se va a presentar organizado a partir de las preguntas que definen los objetivos de la investigación, tratado en primer lugar en una aproximación comparativa la composición de las listas de los partidos, para continuar con la función de las celebridades y la música en la campaña y finalizar con un análisis de los posibles objetivos sociodemográficos detrás de la elección de temas y estilos.

\subsection{Canciones e intérpretes en las playlist}

La primera cuestión es determinar qué canciones e intérpretes comparten las listas de los tres partidos. Para ello se observarán los posibles solapamientos en las listas. Es decir, hasta qué punto los tres partidos considerados llegan a compartir intérpretes o canciones, o si por el contrario las listas están diseñadas para ofrecer un perfil propio y diferenciado. La heterogeneidad de las canciones e intérpretes ya anticipan que serán escasos los puntos de encuentro musical entre los tres partidos, con un total de 263 intérpretes y 287 canciones diferentes.

Tal y como se aprecia en la tabla 6, el 91,9 de las canciones son únicas para cada uno de los partidos considerados. Un $2 \%$ de canciones son compartidas entre PSOE y Ciudadanos y un 6\% entre Ciudadanos y el PP. Siete interpretadas en castellano y 2 en inglés. Se observa una cierta contigüidad ideológica entre los partidos que comparten canciones. Así, entre PSOE y Ciudadanos por una parte, Ciudadanos y PP por otro, y donde no existen canciones compartidas entre PP y PSOE. 
Tabla 6. Canciones compartidas en la playlist electoral del PSOE, PP y Ciudadanos

\begin{tabular}{|l|c|}
\hline & Porcentaje \\
\hline Específicas de cada partido & 91,9 \\
\hline PSOE-Ciudadanos & 2,0 \\
\hline Ciudadanos-PP & 6,0 \\
\hline Total & 100 \\
\hline
\end{tabular}

Fuente: elaboración propia

En lo que se refiere a intérpretes, mantener la diversidad es en principio objetivamente más difícil, dado que la población que pueda ser objeto de interés es más limitada que la de canciones. Aun así, un 77,6\% de los intérpretes son exclusivos de las listas de cada partido. Dentro de dicha limitación, los partidos que comparten mayor número de intérpretes son el PSOE y Ciudadanos (5,7\%), y Ciudadanos con el PP (12,8\%). En el caso del PSOE con el PP comparten un 2,7\% de los intérpretes totales. En todo caso, que los partidos compartan intérpretes no implica que elijan las mismas canciones, como hemos visto anteriormente. PSOE y PP comparten los intérpretes siguientes: Los Manolos, Raffaela Carrá, Rosalía y The Beatles.

Tabla 7. Artistas compartidos en la playlist electoral del PSOE, PP y Ciudadanos

\begin{tabular}{|l|c|}
\hline & Porcentaje \\
\hline Específicas de cada partido & 77,6 \\
\hline PSOE-PP & 2,7 \\
\hline PSOE-CIUDADANOS & 5,7 \\
\hline CIUDADANOS-PP & 12,8 \\
\hline PSOE-PP-CIUDADANOS & 1,3 \\
\hline Total & 100 \\
\hline
\end{tabular}

Fuente: elaboración propia

En el caso de los intérpretes la proximidad mayor es entre las listas de Ciudadanos y el PP, seguida de las listas del PSOE y Ciudadanos. Si las coincidencias hablan de proximidad, la especificidad habla de refuerzo del perfil. En ese sentido, tanto el PP como Ciudadanos repiten intérpretes, si bien en una lógica diferenciada. El PP repite con dos canciones de Los Del Río (sevillanas) y Ciudadanos repite con cinco intérpretes: Avicii, Katy Perry, Miley Cyrus, Selena Gómez y Seguridad Social. De los cinco, cuatro interpretan canciones en inglés. El PSOE no repite ningún intérprete en sus listas.

El análisis de la distribución de las canciones muestra que el solapamiento entre las listas es mínimo, produciéndose entre partidos ideológicamente contiguos. Así, el mayor solapamiento es entre las listas del PP y las de Ciudadanos, y entre el PSOE y Ciudadanos. En el caso de los intérpretes aparecen varios compartidos, si bien en especial los de idioma inglés. No se comparten canciones entre partidos ideológicamente distantes, y en los casos en que comparten intérpretes difieren en la canción elegida. Cabe concluir que unas listas tan diferenciadas ideológicamente persiguen trasmitir un 
mensaje con el propósito de ofrecer una imagen. Vamos a considerar seguidamente en qué forma y con qué mensajes o conexiones emocionales.

\subsection{La música de campaña}

El segundo objetivo es determinar la función de la música y hasta qué punto está presente la "música en campaña". Para ello se debe considerar el compromiso ideológico del intérprete en la selección efectuada de las canciones. En el caso de que un partido incluya en su lista musical artistas que no son afines ideológicamente, estará dando peso a la canción y sus atributos emocionales, de forma que el artista y su posible compromiso ideológico queda relegado a un segundo plano.

Como es bien conocido, no es habitual que los intérpretes musicales se comprometan políticamente. Existen músicos que han conservado su compromiso político con partidos desde la época de la transición a la democracia, como Ana Belén, Víctor Manuel, Serrat y otros artistas que en el trascurso del tiempo han actuado en mítines y actos de partidos políticos, como Celtas Cortos, Danza Invisible o Rozalén. Para clasificar ideológicamente a los intérpretes se ha efectuado una búsqueda exhaustiva de declaraciones en medios de comunicación donde manifiesten su posicionamiento ideológico, así como en función de su participación en actos y mítines de campaña. En dicha búsqueda, también se han considerado los vetos políticos a sus actuaciones. Con frecuencia los gobiernos locales o autonómicos han censurado la actuación de músicos por su posicionamiento político. Este hecho se observa con mayor frecuencia en los ámbitos locales y autonómicos, y particularmente en los periodos de cambio de gobiernos con diferente orientación política. La censura es una evidencia de que dichos músicos, desde la óptica del partido que las aplica, se encuentran catalogados ideológicamente en un sentido u otro. Tras la búsqueda se han clasificado los intérpretes según su afinidad ideológica progresista, conservadora o sin atribuir.

El análisis de la congruencia entre el posicionamiento ideológico de los intérpretes y el partido político que los usa muestra que, en términos generales, no existe coherencia en ese sentido. En la lista del PSOE un 13,8 de los intérpretes son de ideología progresista, un $1,5 \%$ conservador y el $84,6 \%$ no se ha definido públicamente. En el caso del Partido Popular el $20 \%$ de sus intérpretes son progresistas, un $24,4 \%$ conservadores y el $55,6 \%$ sin atribuir. Por último, Ciudadanos es el partido con más intérpretes que se han definido políticamente como progresistas, con $36,6 \%$, un $7,3 \%$ conservador y el $56,1 \%$ sin definir. 
Tabla 8. Posicionamiento ideológico de los intérpretes según partidos

\begin{tabular}{|l|l|c|c|c|c|}
\hline \multirow{2}{*}{ Interprete } & PSOE & PP & Ciudadanos & \\
\cline { 2 - 6 } & Progresista & $13,8 \%$ & $20,0 \%$ & $36,6 \%$ & $21,9 \%$ \\
\cline { 2 - 6 } & Conservador & $1,5 \%$ & $24,4 \%$ & $7,3 \%$ & $9,9 \%$ \\
\cline { 2 - 6 } & Sin atribuir & $84,6 \%$ & $55,6 \%$ & $56,1 \%$ & $68,2 \%$ \\
\hline \multirow{2}{*}{ Total } & $100 \%$ & $100 \%$ & $100 \%$ & $100 \%$ \\
\hline
\end{tabular}

En términos prácticos, los partidos conservadores han utilizado más intérpretes con ideología progresista que el partido socialista. Los datos anteriores parecen sugerir un fenómeno que ha sido generalizado en las campañas de Estados Unidos de América y que, en algunos casos, ha encontrado reflejo en España. Así, Trump ha utilizado cantantes progresistas, algunos de los cuales han denunciado públicamente que emplee sus canciones. Esto ha sucedido en España con VOX, un partido de extrema derecha y su desvío lírico de la canción de Juanes A dios le pido. La existencia de denuncias en el caso norteamericano confirma la idea de fondo de lo observado para el caso español. La canción es útil para el mensaje que quiere lanzar el partido independientemente de la ideología del intérprete.

La discrepancia entre el compromiso ideológico del intérprete y el partido que lo utiliza es un fenómeno que se da por tres circunstancias. La primera, porque los temas de algunas canciones se han desvinculado de las ideas de los intérpretes, particularmente en el caso de las canciones más antiguas y comerciales. Segundo, las canciones con mayor éxito comercial lo son también de audiencia, teniendo estas un alcance más trasversal en los electorados. Por ello algunas canciones pueden ser utilizadas por un partido conservador aun cuando su compositor no lo sea y viceversa. La tercera razón es la potencialidad de connotación que facilita el desvío lírico, generando un significado diferente al original. Un ejemplo de esto es el empleo de la canción de Cecilia Mi querida España por el Partido Popular. Una canción cuya letra fue censurada, crítica con el franquismo, pero cuyo estribillo la convierte para un votante conservador en un mensaje emocional simple y directo. Estos tres elementos permiten el mayor peso de la canción sobre el intérprete en la música de campaña de 2019.

El otro indicador de la naturaleza de música de campaña es la presencia mayoritaria de intérpretes sin compromiso ideológico conocido. El 84\% de los intérpretes que incluye el PSOE en sus playlist no tienen un compromiso político con ningún partido. Son los temas de las canciones lo que es sustantivo para el mensaje. En conjunto, en las listas musicales de los tres partidos considerados prima el uso de la música de campaña, en la medida que la imagen pública de los famosos no es realmente el mensaje; tal es así que su imagen pública no interfiere o distorsiona el significado emocional de la canción. La canción, y no tanto el intérprete, es el mensaje. En otras palabras, las canciones son utilizada como música de campaña, conformando un clúster musical. Este conjunto de canciones define un discurso emocional que apela, de forma segmentada, a la memoria y experiencia vital de los electorados. 


\subsection{La tematización ideológica y emocional}

Un tercer objetivo, dado que las canciones definen el mensaje, es en qué medida sus estilos musicales y los temas tratados pueden llegar a expresar un perfil ideológico que permita diferenciar entre los tres partidos. Desde el punto de vista de la ideología política, el Partido Socialista Obrero Español se identificaría con una óptica progresista, el partido Ciudadanos se autodefine como partido de centro y el Partido Popular desea ofrecer una imagen de centro derecha. La pregunta es por lo tanto, si es posible observar contigüidades y divergencias ideológicas entre partidos a partir de los contenidos temáticos y los estilos musicales de sus playlist de campaña.

En principio, la competición o el deseo de ocupar un espacio político debería expresarse en los temas de las canciones elegidas así como en sus estilos musicales. En otras palabras, si las canciones son vehículos para conectar con los electorados, así como una carta de presentación del partido, deberían apreciarse en las canciones y los estilos musicales elegidos.

En relación con los estilos musicales, es importante recordar que cada uno de ellos posee sus propios atributos emocionales (Alaminos-Fernández, 2019). Así, por ejemplo, en España la música heavy metal o punk se identifica con lo agresivo y lo violento, la música Pop presenta una imagen convencional, y el Indie se tiende a asociar con la canción de denuncia social, sobre todo tras los movimientos sociales de 2011 (del Val y Fouce, 2016; Alaminos-Fernández, 2021). Estos rasgos son atributos estereotipados socialmente, de forma que la imagen de un aficionado al heavy metal es muy diferente al que escucha boleros o música punk. En la práctica, los estilos musicales constituyen un rasgo diferencial muy importante en la configuración de las llamadas tribus urbanas, junto a otros atributos estilísticos y de imagen que han sido utilizados profusamente en la actividad publicitaria.

La primera observación significativa es la ausencia de estilos que se puedan considerar extremadamente agresivos, como el punk o el heavy metal. Considerando las canciones en castellano, los estilos más frecuentes acumulan el $75 \%$ de las canciones y son el pop con el $51 \%$ de las canciones, rock un $16,6 \%$ y la música alternativa/indie el 7,4\%. El resto, un $25 \%$ de las canciones se distribuyen de forma testimonial en múltiples estilos como son la copla, cantautor, dance/música electrónica, electropop, flamenco, hip-hop/rap, house, música electrónica, nuevo flamenco, pasodoble, R\&B, reguetón, rumba, salsa y sevillanas.

El análisis de los estilos musicales elegidos por los tres partidos para sus listas muestra diferencias estadísticamente significativas. La tabla 9 muestra la no independencia entre partidos políticos y estilos musicales, con un chi-cuadrado de Pearson de 48,556 para 4 grados de libertad y una significación asintótica (bilateral) del ,000. En la práctica los coeficientes muestran que existe asociación entre las dos variables. 
Tabla 9. Estilos musicales según partidos políticos

\begin{tabular}{|l|c|c|c|c|}
\hline & PSOE & PP & Ciudadanos & Total \\
\hline Nuevos estilos & $44,4 \%$ & $8,9 \%$ & $2,4 \%$ & $22,1 \%$ \\
\hline Estilos modernos & $52,4 \%$ & $68,9 \%$ & $97,6 \%$ & $69,8 \%$ \\
\hline Estilos tradicionales & $3,2 \%$ & $22,2 \%$ & & $8,1 \%$ \\
\hline & $100 \%$ & $100 \%$ & $100 \%$ & $100 \%$ \\
\hline
\end{tabular}

Fuente: elaboración propia

Los "nuevos estilos" son utilizados sobre todo por el Partido Socialista Obrero Español con un 44,4\% de sus canciones de este tipo. Este es mucho más testimonial en el Partido Popular (8,9\%) o Ciudadanos (2,4\%). Los estilos "modernos" están presentes en todos los partidos políticos, destacando el caso de Ciudadanos con un 97,6\% de sus canciones. Es también el núcleo de la lista del Partido Popular (68,9\%) y el Partido Socialista Obrero Español $(52,4 \%)$. La apelación a un amplio espectro de población, de carácter más convencional, es el núcleo de las playlist de los partidos conservadores. En el caso de los "estilos tradicionales" el Partido Popular, con un 22,2\% de sus canciones es el que las utiliza en mayor medida. En el Partido Socialista Obrero Español es un 3,2\% y no están presentes en las listas de Ciudadanos. La estructura relacional existente entre los estilos y los partidos políticos se aprecia claramente mediante un análisis de correspondencias del gráfico 1 .

Gráfico 1. Análisis de los estilos musicales y los partidos políticos

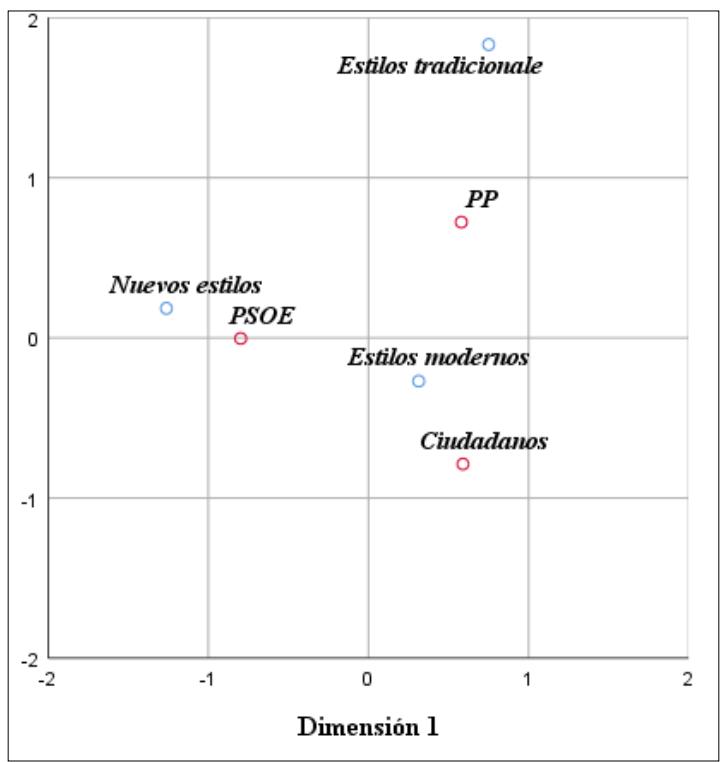

Fuente: elaboración propia. Normalización simétrica 
Se observa como los nuevos estilos son característicos del PSOE, al igual que los estilos tradicionales lo son del PP. Los estilos modernos, si bien son por proximidad importantes para Ciudadanos, también tienen un peso gravitatorio significativo en las listas de los otros dos partidos.

Si consideramos los estilos musicales, destaca la mayor presencia de los más comerciales y convencionales en los tres partidos; son estilos cómodos para la población en general. En su momento expresaron modernidad para las generaciones de mayor edad, y su continuidad en el tiempo los ha hecho muy familiares para el conjunto de la sociedad. Este es el rasgo fundamental de Ciudadanos, que hace de estos géneros (pop y rock) la clave de arco de su mensaje musical. En el caso del Partido Popular el empleo de estilos tradicionales apela musicalmente a los segmentos de población más identificados con la idea de patria y de España. Es algo que confirma el análisis de las temáticas, como veremos seguidamente.

El partido que apuesta en mayor grado por los jóvenes, la actualidad y la diversidad es el Partido Socialista Obrero Español. Casi la mitad de sus canciones expresan estilos con audiencias segmentadas y algunas con una imagen marcadamente progresista, como es el indie. Asimismo, los contenidos de sus letras, en varios casos de denuncia social, son consistentes con dicha presentación musical. Las canciones del partido socialista corresponden con gustos musicales mucho más específicos que en el caso de los otros partidos, concediendo un mayor peso a la diversidad de estilos de la población juvenil.

La preferencia por un estilo u otro conlleva una evidente marca temporal. Los estilos más novedosos no pueden ser familiares para las generaciones de mayor edad, cuyo contacto con dichos géneros musicales es más indirecto (por ejemplo a través de los hijos). Según diversos estudios, la adolescencia y la juventud son las etapas etarias donde las canciones se impregnan emocionalmente en mayor grado, especialmente a partir de las experiencias personales. En todo caso, los límites entre generaciones, al igual que entre climas culturales, son borrosos no existiendo una delimitación precisa y categórica entre ellas. En la tabla 10 se aprecia la no independencia entre partidos políticos y las décadas musicales de sus canciones, con un chi-cuadrado de Pearson de 31,114 para 10 grados de libertad y una significación asintótica (bilateral) del ,001. Los coeficientes de asociación indican que en la práctica esta existe entre las dos variables.

Tabla 10. Fechas de lanzamiento de las canciones según partidos

\begin{tabular}{|c|c|c|c|c|}
\hline & PSOE & PP & Ciudadanos & Total \\
\hline $1965-1975$ & $1,6 \%$ & $11,1 \%$ & & $4,0 \%$ \\
\hline $1976-1985$ & $4,8 \%$ & $17,8 \%$ & $19,5 \%$ & $12,8 \%$ \\
\hline $1986-1995$ & $7,9 \%$ & $15,6 \%$ & $19,5 \%$ & $13,4 \%$ \\
\hline $1996-2005$ & $17,5 \%$ & $26,7 \%$ & $14,6 \%$ & $19,5 \%$ \\
\hline $2006-2015$ & $33,3 \%$ & $15,6 \%$ & $9,8 \%$ & $21,5 \%$ \\
\hline $2016-2019$ & $34,9 \%$ & $13,3 \%$ & $36,6 \%$ & $28,9 \%$ \\
\hline Total & $100 \%$ & $100 \%$ & $100 \%$ & $100 \%$ \\
\hline
\end{tabular}

Fuente: elaboración propia 
En las listas del Partido Socialista Obrero Español casi el 70\% de sus canciones son posteriores a 2006. Esto, en interacción con los estilos, sugiere un mayor compromiso con las generaciones más jóvenes. En el caso de Ciudadanos se observa una doble gravitación sobre los más jóvenes y la generación de la “movida”. Sobre los más jóvenes con el 36,6\% de sus canciones posteriores a 2016, y los más maduros correspondiendo el $40 \%$ de las canciones con el postfranquismo y la época cultural de la movida. El Partido Popular utiliza una lista de más amplio espectro generacional. Partiendo de la etapa del desarrollismo franquista de la década de los 60, continúa con la transición y la movida, eleva el número de canciones en la época de los gobiernos de Aznar para llegar hasta la actualidad. El Partido Popular apela musicalmente a todas las generaciones, incluyendo en el foco a los de mayor edad. Recordemos que los electorados del Partido Popular tienen una composición demográfica envejecida, a la que se dirige con la nostalgia musical como puente emocional. Uno de los objetivos estratégicos del Partido Popular era recuperar electores desmovilizados o en duda, y este tipo de músicas da la impresión de estar orientado más a la recuperación de antiguos votantes que a la captación de otros nuevos.

En todo caso, se busca el recurso a la memoria emocional de los electorados del modo más intergeneracional posible. Con dicha finalidad destacan dos elementos en el diseño de las playlist. En primer lugar, la elección de canciones tipo que representan un estilo y una época. Es lo que Adorno (1946) definía como canciones que expresan el "patrón oro” del estilo musical de una época. Así, canciones como Que Se Mueran los Feos de Los Sirex (1965), Marisol y Corazón Contento (1968), Raphael con Mi gran noche (1968), Nino Bravo interpretando Libre (1972) o Las Grecas con Te Estoy Amando Locamente (1974). Son canciones que aparecen habitualmente en las selecciones de éxitos de oro de la música española, identificando de forma arquetípica un estilo, una época y clima emocional. En ese sentido, a pesar de su antigüedad, si bien expresan un mensaje especial para una generación (los de mayor edad) conserva el componente de popularidad que las mantiene con vitalidad cultural.

Otro segundo elemento que opera transversalizando generacionalmente las canciones más antiguas es la actualización de las versiones; ya sean con nuevos intérpretes que la ponen nuevamente de moda o con los intérpretes originales en una nueva versión. En la primera categoría se encuentran Muchachito Bombo Infierno con La quiero a Morir en 1998 (versión original de 1979), Las Chillers y Mujer contra mujer interpretada en el 2018 (original de 1988), Niños mutantes Como yo te amo en 2007 (original de 1980). En la segunda categoría, la actualización del éxito por los mismos intérpretes, aparecen Shakira y Alejandro Sanz con La tortura, Miguel Bosé y Bimba Bosé Como un lobo, Calle 13 y Silvio Rodríguez en Ojos Color Sol, Bombai y Bebe Solo si es contigo, Barricada, Rosendo y Aurora Beltrán en "Maneras de vivir". Las dos estrategias incrementan la trasversalidad generacional, al ser canciones que representan una época en los términos que propone Adorno o actualizando la canción al volver a introducirla años más tarde en la lista de los grandes éxitos.

Otro elemento que puede caracterizar el mensaje de los partidos políticos a través de sus playlist son los temas tratados en las canciones. En ese sentido, en relación con las elecciones presidenciales norteamericanas del 2020, el análisis del New York Times sobre las canciones de campaña elegidas por los líderes políticos norteamericanos estableció una clara asociación entre ideología y tema de las canciones. Así, Bernie Sanders, en su playlist, quiso enfatizar el espíritu "revolucionario" e innovador de su campaña, utilizando canciones que tenían frases como "poder para el pueblo", "revolución”, “cambio", contenidas en canciones como Power to the People de John Lennon. Biden, por su parte, siguió la estrategia ya 
empleada por Obama (Alaminos-Fernández, A.F, 2018) al utilizar de forma equilibrada temática y racialmente canciones que le presentaban ante los votantes como el político de la clase media (Middle Class Joe).

Una primera observación sobre las letras de las canciones es que, salvo manipulación lírica, las elecciones se hacen sobre el repertorio disponible. Son canciones que deben ser, además, bien conocidas para la población que es objeto de atención. En dicho contexto, enfatizar unas temáticas respecto a otras implica como consecuencia elegir determinados estilos y épocas. Por ejemplo, utilizar canciones que destaquen la lucha contra la violencia de género excluye décadas y décadas de música popular en España. A nadie puede sorprender que los temas predominantes en las últimas décadas hayan sido las relaciones de pareja, ya sea en clave romántica o incorporando recientemente una sexualización explícita. Al diseñar una lista de canciones populares con finalidad electoral existe, en ese sentido, una dependencia y limitación temática procedente de la industria musical. Las canciones son uno de los productos que se comercializan en el mercado y los patrones de composición musical responden a las necesidades de este. Dichas limitaciones enmarcan las elecciones posibles para las playlist electorales.

En la tabla 11 se presenta la distribución de los temas de las canciones según las playlist de los partidos. Se observa la no independencia entre partidos políticos y los temas musicales de sus canciones, con un chi-cuadrado de Pearson de 34,729 para 6 grados de libertad y una significación asintótica (bilateral) del ,000. Nuevamente, los coeficientes de asociación indican que existe entre las dos variables.

Tabla 11. Temas de las canciones según partido político

\begin{tabular}{|l|c|c|c|c|}
\hline & PSOE & PP & Ciudadanos & Total \\
\hline Estados de ánimo personales & $31,7 \%$ & $40,0 \%$ & $29,3 \%$ & $33,6 \%$ \\
\hline Emociones románticas pareja & $38,1 \%$ & $44,4 \%$ & $61,0 \%$ & $46,3 \%$ \\
\hline Sociopolíticas sectorial & $30,2 \%$ & & $7,3 \%$ & $14,8 \%$ \\
\hline Sociopolíticas identitarias & & $15,6 \%$ & $2,4 \%$ & $5,4 \%$ \\
\hline Total & $100 \%$ & $100 \%$ & $100 \%$ & $100 \%$ \\
\hline \multicolumn{5}{|c|}{ Fuente: elaboración propia }
\end{tabular}

En las listas del Partido Socialista Obrero Español no aparecen canciones de naturaleza identitaria. Comparte con los demás partidos la presencia de los temas más frecuentes en la música comercial española y que expresan estados emocionales individuales $(31,7 \%)$ o de relación romántica $(38,1 \%)$. Contiene como especificidad la presencia significativa de canciones con temas sociales $(30,2 \%)$ que tratan la violencia de género, la desigualdad, el empoderamiento femenino, la libertad sexual, etc. Ya hemos observado la consecuencia de dicha elección temática, tanto en términos de estilos musicales como de las fechas de las canciones.

El Partido Popular elige también canciones que expresan preferentemente estados emocionales individuales (40\%) o de relación romántica (44,4\%). Aparecen, como rasgo característico las canciones que ensalzan el ser español (15,6\%). La identidad nacional y los rasgos regionalistas tradicionales forman parte de su discurso ideológico. 
La lista de Ciudadanos es la única de las tres que contiene las cuatro temáticas, si bien más desproporcionada entre categorías. El 61,9\% de sus canciones tratan la temática de las relaciones románticas. De acuerdo con las reglas de codificación establecidas, se trata de relaciones románticas heterosexuales. Un 29,3\% de las canciones expresan estados emocionales individuales. En conjunto, el $91 \%$ de las canciones son egocéntricas, tanto en las experiencias de la relación de pareja como de estado de ánimo. Un 14,8\% de las canciones ofrecen temas de contenido social, como por ejemplo “Girasoles" de Rozalen. Contiene también una referencia identitaria en el 2,4\% de sus canciones.

El análisis de correspondencias del gráfico 2 muestra nuevamente el patrón relacional entre partidos y temas. Los que tratan temas de naturaleza sociopolítica, como la violencia de género o la desigualdad, son característicos de la lista de canciones del Partido Socialista Obrero Español. Los temas identitarios o idiosincráticos son atributos propios del Partido Popular. En los dos partidos contribuyen a su perfil canciones que expresan estados de ánimo. En Ciudadanos priman de forma distintiva las emociones románticas, si bien también participa de los estados de ánimo personales. En Ciudadanos, a diferencia del Partido Popular, sus canciones gravitan sobre el individuo y sus emociones personales.

Gráfico 2. Temas de las canciones según los partidos políticos

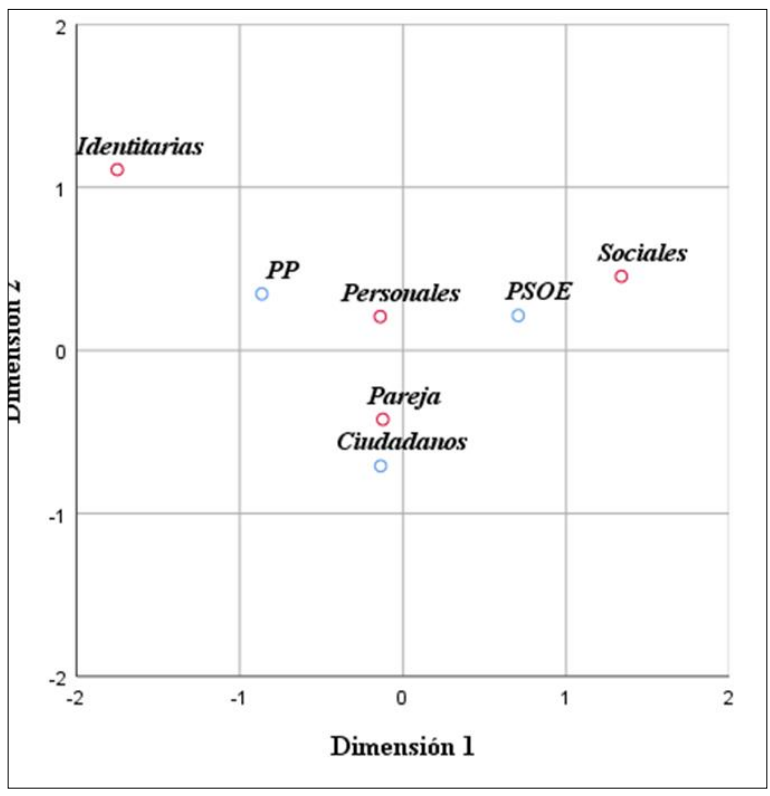

Fuente: elaboración propia. Normalización simétrica

La aparición de temáticas generalistas como son los estados de ánimo y las relaciones afectivas definen el puente emocional que pretende humanizar a los partidos. En ese efecto de personificación los partidos sienten como el elector, sufren angustias vitales y comprenden el dolor que casusa el amor o el desengaño. No es un mensaje con contenido social que 
apele a un tema significativo políticamente, como es la violencia de género, la igualdad o la patria. Mensajes dirigidos a la razón y el cerebro. Su mensaje es puramente emocional, buscando la proximidad empática con los electorados. Esa parte de sus playlist aspira a ser el alma y el corazón del partido que se abre a los demás. En ese sentido, las playlist electorales de los partidos en las elecciones de 2019 en España contienen más parte de corazón (emoción) que de cerebro (razón).

\section{Conclusión y debate}

El análisis de las playlists electorales de los partidos permite establecer varias conclusiones empíricas. En primer lugar, los partidos considerados buscan establecer un perfil musical propio, y con dicho objetivo, se maximiza la diferenciación recurriendo a intérpretes y canciones diferentes de los otros partidos. En ese proceso de elegir las canciones, se observa cómo las coincidencias en intérpretes y canciones conservan la estructura de posicionamiento ideológico. Así, canciones e intérpretes en las listas del PSOE coinciden con la playlist de Ciudadanos, y las de este partido con la del PP. Sin embargo, no existe coincidencia significativa entre las listas del PSOE y del PP. El único interprete común a los tres partidos es Queen, y aun siendo el mismo intérprete, utilizan canciones diferentes.

Otra conclusión es el mayor peso funcional de la canción respecto al del intérprete, evidenciado en los partidos de derechas que utilizan indiscriminadamente intérpretes que se han posicionado ideológicamente en la izquierda. En ese sentido, el factor fama queda relegado a un segundo plano en favor de los mensajes (emocionales y de contenido) de las canciones, en un uso funcional de la música de campaña. Este fenómeno de disociación se da por tres circunstancias. La primera, que los temas de algunas canciones se han desvinculado de las ideas de los intérpretes, particularmente en el caso de las canciones más antiguas y comerciales. Segundo, las canciones con mayor éxito comercial lo son también de audiencia, teniendo estas un alcance más trasversal en los electorados. Por ello algunas canciones pueden ser utilizadas por un partido conservador aun cuando su compositor no lo sea. La tercera razón es lo que se denomina desvío lírico, donde el significado que atribuye a la canción es diferente al original.

Las canciones y su mensaje al electorado se han analizado generacionalmente, según los estilos musicales y los temas tratados. Las canciones expresan generacionalmente una especie de estratigrafía emocional. En ese sentido, se produce dos recursos para activar las memorias generacionales intentando darles el más amplio espectro etario. En primer lugar, la elección de canciones tipo que representan un estilo y una época, expresando el "patrón oro" del estilo musical de una época. El segundo elemento que opera transversalizando generacionalmente las canciones más antiguas es utilizar versiones actualizadas que han aparecido nuevamente en los rankings musicales.

Los estilos, las generaciones y los temas se encuentran entrelazados entre sí. De este modo los temas con contenido social (presentes en las playlist socialistas) recurren a los estilos musicales más recientes, que son los que han incorporado a sus letras dichos temas. En el otro extremo, las canciones con fuerza identitaria emplean estilos más tradicionales como la copla o el pasodoble, propios de épocas más pasadas, como es el caso de las listas del Partido Popular. Los estilos más convencionales considerados modernos (pop o rock) tienden a tratar estados de ánimo personales o tensiones emocionales de pareja, y son de amplio espectro generacional desde la década de los 60 . Estos géneros musicales y temas son los más habituales en las playlist de Ciudadanos, si bien empleando canciones más actuales. En términos sociodemográficos, en 
el PSOE se aprecia una apuesta por los jóvenes y los temas sociales más de actualidad, mientras que el Partido Popular, dentro de una apelación generacionalmente amplia, recurre a la nostalgia y la identidad como elementos diferenciales. Más en la lógica de recuperar y movilizar antiguos votantes que de captar nuevos. Ciudadanos diseña una lista que, partiendo del posfranquismo, se detiene profusamente en la época de la denominada "movida". Demográficamente se orienta especialmente a la captación de electorados maduros y jóvenes. En cualquier caso, lo más destacable es la escasez de mensaje político. Una parte sustantiva de las listas actúan en el plano emocional buscando la proximidad e identificación de los electorados mediante la humanización del partido. Un partido que se personaliza y adquiere alma gracias a compartir canciones con estados de ánimo personales, crisis existenciales e incluso amorosas.

\section{Referencias bibliográficas}

Adorno, T.W. (1941) “On Popular Music,” Studies in Philosophy and Social Sciences (1941), Vol. IX, No. 1. Páginas 17-48. https://doi.org/10.5840/zfs1941913

Alaminos A. (2021) Las dinámicas de cambio en el comportamiento del electorado en España. Revista Sistema, nº 260, enero. págs. 17-34.

Alaminos-Fernández (2016) Música en campaña. El activismo de las celebridades internacionales en causas sociales y solidarias. Alicante: Obets-Limencop.

Alaminos-Fernández A. (2021) La caracterización musical transmedia de las identidades juveniles: el caso de la serie Stranger Things. Fonseca, Journal of Communication 21 (19), 87-105. https://doi.org/10.14201/fjc20202187105

Alaminos-Fernández, A. F (2017). Obamas Tracklist: Proyectando Una Imagen Pública A Través De La Música. Comunicación Política y Redes Sociales en ChavesMontero, A. (2017) Comunicación Política y Redes Sociales, Egregius. 137-155. http://hdl.handle.net/10045/110995

Alaminos-Fernández, A. F y Alaminos-Fernández, P. (2020) Los conciertos solidarios y la movilización sociopolítica: límites y potencialidades en Encabo, E (2020) Música y pantallas. Cultura, sociedad, educación. Editorial Difácil.

Alaminos-Fernández, A. F. (2019). La realidad aumentada. Música y comunicación en la sociedad de consumo. Tesis doctoral. Universidad de Alicante. http://hdl.handle.net/10045/103127

Alaminos-Fernández, A.F. (2021) “El efecto del contexto social en la asociación entre música y emoción”. OBETS. Revista de Ciencias Sociales, 16(1): 17-34. https://doi.org/10.14198/OBETS2021.16.1.01

Alonso González C. (coord.) (2010) Creación musical, cultural popular y construcción nacional en la España contemporánea. Madrid: Instituto Complutense de Ciencias Musicales

Balte, F. R., Avram, J., Miclea, M., y Miu, A. C. (2011). Emotions induced by operatic music: Psychophysiological effects of music, plot, and acting: A scientist's tribute to Maria Callas. Brain and cognition, 76(1), 146-157. https://doi.org/10.1016/j. bandc.2011.01.012 
Bechini Tejados, A. (1985) El diferencial semántico de la lengua catalana. Barcelona: Edicions Universitat de Barcelona Brownell K. C. (2014) Showbiz Politics: Hollywood in American Political Life. Chapel Hill: UNC Press Books

Brownell K.C. (2015) Showbiz politics: through campaign songs, candidates become stars. Accesible en https:// theconversation.com/showbiz-politics-through-campaign-songs-candidates-become-stars-40043

Burke K. (1969) A Rhetoric of Motives. Berkeley: University of California Press

Busby, R. (2009) Marketing the Populist Politician: The Demotic Democrat. London: Palgrave Macmillan. https://doi. org/10.1057/9780230244283

DeWall, C. N., Pond Jr, R. S., Campbell, W. K., y Twenge, J. M. (2011). Tuning in to psychological change: Linguistic markers of psychological traits and emotions over time in popular US song lyrics. Psychology of Aesthetics, Creativity, and the Arts, 5(3), 200. https://doi.org/10.1037/a0023195

Espí Hernández A. (2017) Una propuesta de medición de emociones en las elecciones Generales 2016 en España. Más poder local, No. 32, págs. $42-50$

Fouce H. (2009) De la agitación a la Movida: Políticas culturales y música popular en la Transición española. Arizona Journal of Hispanic Cultural Studies, ISSN 1096-2492, No. 13, págs. 143-154. https://doi.org/10.1353/hcs.0.0066

Fouce, H y del Val Ripollés F. (2017) Indignación y política en la música popular española: El imaginario de los videoclips independientes. Signa: Revista de la Asociación Española de Semiótica, ISSN 1133-3634, No 26, págs. 663-675. https://doi. org/10.5944/signa.vol26.2017.19921

Fouce, H. y Pecourt J. (2008) Emociones en lugar de soluciones música popular, intelectuales y cambio político en la España de la Transición Revista Transcultural de Música, №. 12, 2008

García Moriyón, F. (2019) Emociones y política. Crítica. N. 1039. Enero

García Peinazo D. (2017) Rock andaluz: significación musical, identidades e ideología en la España del tardofranquismo y la transición (1969-1982). Madrid: Sociedad Española de Musicología (Colección Estudios-30) https://doi. org $/ 10.2307 / 24878588$

Gibson, R., Aust, C. F, y Zillmann, D. (2000). Loneliness of adolescents and their choice and enjoyment of lovecelebrating versus love-lamenting popular music. Empirical Studies of the Arts, 18(1), 43-48. https://doi.org/10.2190/ B51G-8U0W-N0EQ-MJUU

Giles, D. C., y Maltby, J. (2004). The role of media figures in adolescent development: Relations between autonomy, attachment, and interest in celebrities. Personality and individual differences, 36(4), 813-822. https://doi.org/10.1016/ S0191-8869(03)00154-5

Harakeh, Z., Scholte, R. H., Vermulst, A. A., de Vries, H., \& Engels, R. C. (2004). Parental factors and adolescents' smoking behavior: an extension of the theory of planned behavior. Preventive medicine, 39(5), 951-961. https://doi.org/10.1016/j. ypmed.2004.03.036 
Hargreaves, D. J., Miell, D., y MacDonald, R. A. (2002). What are musical identities, and why are they important. Musical identities, 2, 1-20.

Heath, C., Bell, C., y Sternberg, E. (2001). Emotional selection in memes: the case of urban legends. Journal of personality and social psychology, 81(6), 1028. https://doi.org/10.1037/0022-3514.81.6.1028

Jaráiz, E. Lagares, N. y Pereira, M. (2020). Emociones y decisión de voto. Los componentes de voto en las elecciones generales de 2016 en España. Revista Española de Investigaciones Sociológicas, 170: 115-136. http://dx.doi.org/10.5477/ cis/reis. 170.115

Juslin, P. N. (2005). From mimesis to catharsis: expression, perception, and induction of emotion in music. En Miell, D., MacDonald, R. y Hargreaves D. Musical communication, Oxford University Press, New York, p. 85-115. https://doi. org/10.1093/acprof:oso/9780198529361.003.0005

Labrador Méndez, G. y Monasterio Baldor A. (2006) Canciones para después de una dictadura. El Rapto de Europa: crítica de la cultura, No. 9, 2006, págs. 35-48

Love,J.“PoliticalPopandCommercialsthatFlopped:EarlyLessonsfromthe2016PresidentialRace,”TraxontheTrail,January14, 2016, http://traxonthetrail.com/article/political-pop-and-commercials-flopped-early-lessons-2016-presidential-race.

Love, J. “Branding a Cool Celebrity President: Advertising with Popular Music in the 2012 Election," Music \& Politics 9, no. 2 (2015), https://doi.org/10.3998/mp.9460447.0009.203

Maxwell, K. A. (2002). Friends: The role of peer influence across adolescent risk behaviors. Journal of Youth and adolescence, 31(4), 267-277. https://doi.org/10.1023/A:1015493316865

Mora, K. y Viñuela E. (eds.) (2013) Rock around Spain: Historia, industria, escenas y medios de comunicación. Lleida: Universitat de Lleida.

Mori, K., y Iwanaga, M. (2014). Pleasure generated by sadness: Effect of sad lyrics on the emotions induced by happy music. Psychology of Music, 42(5), 643-652. https://doi.org/10.1177/0305735613483667

North, A. C., Hargreaves, D. J., \& Krause, A. E. (2009). Music and consumer behaviour. Oxford handbook of music psychology, 481-490.

Panke, Luciana (2019) Los hinchas en la política. Más poder local, №. 38, págs. 14-15

Pereira, C. S., Teixeira, J., Figueiredo, P., Xavier, J., Castro, S. L., \& Brattico, E. (2011). Music and emotions in the brain: familiarity matters. PloS one, 6(11), e27241.

https://doi.org/10.1371/journal.pone.0027241

Petraitis, J., Flay, B. R., \& Miller, T. Q. (1995). Reviewing theories of adolescent substance use: organizing pieces in the puzzle. Psychological bulletin, 117(1), 67. https://doi.org/10.1037/0033-2909.117.1.67

Quevedo Redondo R. (2017) Personalización, emoción y cercanía: Una estrategia para la captación del voto femenino en año electoral. Comunicación y sociedad Vol. 30, №. 3, 2017, 155-167. 
Rentfrow, P. J., y Gosling, S. D. (2003). The do re mi's of everyday life: the structure and personality correlates of music preferences. Journal of personality and social psychology, 84(6), 1236. https://doi.org/10.1037/0022-3514.84.6.1236

Rolston (2001) This is not a Rebel Song': The Irish Conflict and Popular Music. Race \& Class. Volume: 42 issue: 3, page(s): 49-67. https://doi.org/10.1177/0306396801423003

Rothbaum, F., y Tsang, B. Y. P. (1998). Lovesongs in the United States and China: On the nature of romantic love. Journal of Cross-Cultural Psychology, 29(2), 306-319. https://doi.org/10.1177/0022022198292003

Schoening B.S. y Kasper, E.T. (2012) Don't Stop Thinking About The Music: The Politics of Songs and Musicians In Presidential Campaigns. Lanham: Lexington Books.

Sousou, S. D. (1997). Effects of melody and lyrics on mood and memory. Perceptual and motor skills, 85(1), 31-40. https:// doi.org/10.2466/pms.1997.85.1.31

Stratton, V. N., y Zalanowski, A. H. (1994). Affective impact of music vs. lyrics. Empirical studies of the arts, 12(2), 173-184. https://doi.org/10.2190/35T0-U4DT-N09Q-LQHW

Taylor (2016) Música y capitalismo. Una historia del presente. Chicago: The University of Chicago Press.

Val, F. del y Fouce, H. (2016) De la apatía a la indignación. Narrativas del rock independiente español en época de crisis, Methaodos. Revista de ciencias sociales, 4 (1): 58-72. http://dx.doi.org/10.17502/m.rcs.v4i1.105 https://doi. org/10.17502/m.rcs.v4i1.105

West, D. M. and Orman, J. (2003) Celebrity Politics. Upper Saddle River, NJ: Prentice Hall.

Wheeler, M. (2013): Celebrity politics. Image and identity in Contemporary Political Communicatios. Cambridge, Polity Press, 240. 


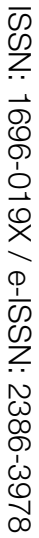

